Econ. Innov. New Techn.

\title{
ASSESSING THE RELATIVE PERFORMANCE OF UNIVERSITY TECHNOLOGY TRANSFER IN THE US AND UK: A STOCHASTIC DISTANCE FUNCTION APPROACH
}

Donald Siegel , Mike Wright, Wendy Chapple \& Andy Lockett

To cite this article: Donald Siegel , Mike Wright, Wendy Chapple \& Andy Lockett (2008) ASSESSING THE RELATIVE PERFORMANCE OF UNIVERSITY TECHNOLOGY TRANSFER IN THE US AND UK: A STOCHASTIC DISTANCE FUNCTION APPROACH, Econ. Innov. New Techn., 17:7-8, 717-729, DOI: 10.1080/10438590701785769

To link to this article: https://doi.org/10.1080/10438590701785769

Published online: 16 Oct 2008.

Submit your article to this journal $\sqsubset$

Џ Article views: 301

Citing articles: 24 View citing articles 


\title{
ASSESSING THE RELATIVE PERFORMANCE OF UNIVERSITY TECHNOLOGY TRANSFER IN THE US AND UK: A STOCHASTIC DISTANCE FUNCTION APPROACH
}

\author{
DONALD SIEGEL ${ }^{\mathrm{a}, *}$, MIKE WRIGHT $^{\mathrm{b}}$, WENDY CHAPPLE ${ }^{\mathrm{b}}$ and ANDY LOCKETT ${ }^{\mathrm{b}}$ \\ ${ }^{a}$ Department of Management and Marketing, A. Gary Anderson Graduate School of Management, \\ University of California at Riverside, Riverside, CA 92521, USA \\ ${ }^{\mathrm{b}}$ Nottingham University Business School, University of Nottingham, Jubilee Campus, Nottingham \\ $N G 81 B B, U K$
}

(Received 1 April 2007; In final form 10 January 2008)

\begin{abstract}
University technology transfer offices (henceforth, TTOs) play a critical role in the diffusion of innovation and the development of new technology infrastructure. Studies of the relative efficiency of TTOs have been based on licensing output measures and data from a single country. In contrast, we present the first cross-country comparison of the relative performance of TTOs, based on stochastic multiple output distance functions. The additional dimension of output considered is the university's propensity to generate start-up companies, based on technologies developed at these institutions. We find that US universities are more efficient than UK universities and that the production process is characterized by either decreasing or constant returns to scale. Universities with a medical school and an incubator are closer to the frontier.
\end{abstract}

Keywords: Technology transfer office; Technology licensing; University spin-offs (USO) patents; Stochastic distance functions

JEL Codes: D23; L31; O31; O32

\section{INTRODUCTION}

In recent years, there has been a substantial increase in the rate of commercialization of intellectual property at US and UK universities. More specifically, universities have attempted to formalize technology transfer and capture a larger share of the economic rents associated with technological innovation by establishing technology transfer offices (henceforth, TTOs). TTOs facilitate technological diffusion through the licensing of a university-based technology to an existing firm or new venture. Thus, they contribute to the development of new technology infrastructure. University technology transfer can also potentially yield economic benefits to the local region, through job and new firm creation or the stimulation of additional research activity in nearby firms.

\footnotetext{
*Corresponding author. E-mail: donald.siegel@ucr.edu
} 
Given the critical managerial and policy implications of university technology transfer, there is considerable interest in assessing and 'explaining' relative performance. Licensing has traditionally been the most popular mode of university technology transfer (Jensen and Thursby, 2001). As a result, several studies have used either the number of licenses or licensing income as the single output.

From the university's perspective, an advantage of licensing as a mechanism for technology transfer is that it allows academics to continue their pursuit of research, without devoting effort to commercialization. However, for certain technologies, patenting and licensing is difficult or infeasible. Thus, an exclusive focus on licensing might prevent universities from reaping a substantial return on their intellectual property portfolio.

Therefore, universities might seek more direct involvement in the commercialization of new technology by 'spinning off' a company (Shane, 2002; Shane and Stuart, 2002). Typically, the university assumes equity in the start-up, and thus, owns a percentage of the company. Siegel et al. (2003b) report that universities are increasingly focusing greater attention on the entrepreneurial dimension of technology transfer. As a result, there has been growing interest in the role of university spin-offs (DiGregorio and Shane, 2003).

With respect to cross-country comparisons, there is a general sense that the UK is not as advanced as the US in university technology transfer. In the UK, this has engendered a policy debate concerning the nature of outputs resulting from university technology transfer. The UK Treasury-sponsored Lambert Review of business-university collaboration (Lambert, 2003) asserted that British universities needed to determine the optimal mix of licensing and spin-off or licensing activity.

This paper takes an account of these two important trends in university technology transfer: (1) the tendency of universities to benchmark their performance against domestic and foreign rivals and (2) the growing emphasis on the entrepreneurial dimension of technology commercialization at universities. More specifically, the study potentially makes two contributions to the literature. The paper contains the first econometric evidence on the relative efficiency of university TTOs that is based on multiple outputs. Specifically, we outline and estimate a stochastic, multiple-output distance function to capture the efficiency of both university licensing and spin-off generation. We also present the first cross-country comparison of the relative performance of university TTOs.

The remainder of this paper is organized as follows. Section 2 outlines our specification of the technology transfer production function and factors that may explain some of the variation in relative performance across universities. Section 3 presents the econometric model, which is based on the specification of a stochastic distance function. Section 4 describes the data and Sec. 5 presents empirical results. Preliminary conclusions and suggestions for additional research are presented in the final section.

\section{INPUTS, OUTPUTS, AND DETERMINANTS OF RELATIVE 'EFFICIENCY' IN UNIVERSITY TECHNOLOGY TRANSFER}

Studies of the effectiveness of university technology transfer of US universities (e.g., Thursby and Kemp, 2002; Thursby and Thursby, 2002; Siegel et al., 2003a) have been based on a production function framework. Several key stylized facts have emerged from field and survey research on TTOs (e.g., Thursby et al., 2001; Siegel et al., 2003a), which are relevant to the specification of this production function. The first is that although faculty members working on a federal research grant are required to disclose inventions to the university TTO, some researchers do not comply with this regulation and the rule is rarely enforced. This aberrant 
behavior highlights the critical task of TTO staff in simply eliciting disclosures from faculty members and thus, increasing the potential pool of potential technologies for licensing. Technology licensing officers can potentially play an important role by providing 'business coaching' and encouraging faculty members to engage in entrepreneurial and licensing activity.

Field research has also revealed that the importance of patents in this process is often overstated. That is, many firms license technologies long before the university patents them, if they are patented at all. This occurs for several reasons. First, patent protection may not be viable or critical for a particular type of technology. For instance, patents are not important in the computer software industry or in the design of integrated circuits. Second, firms may have considerable faith in the scientist's ability or reputation, or because the inventor has a long-standing financial relationship with the firm. ${ }^{1}$ Finally, some firms (especially younger, more entrepreneurial companies) are anxious to lock-in promising embryonic technologies at a low price.

Another stylized fact culled from interviews of licensing officers is the importance of (external) intellectual property lawyers in the process of technology transfer. Some institutions use these lawyers to help them obtain copyrights and in various aspects of patenting and licensing, especially in support of prosecution, maintenance, litigation, and interference. Indeed, it is quite common for universities to devote substantial resources to the maintenance and re-negotiation of licensing agreements, due to the embryonic nature (e.g., uncertainty) of the technologies and to the fledgling nature of many of the firms that license university-based technologies. Therefore, we use legal expenditures as an input into the creation of licenses, licensing income, and university spinouts.

A key difference between the two countries should be noted. In the US, the Bayh-Dole Act stipulates that scientists must disclose inventions arising from federally funded research to the university TTO. There is no such legislation in the UK. The 1997 UK Patent Act states that inventions of employees who may reasonably expect to make inventions are clearly owned by the employer, so long as it is stated in the employment contract. If ownership is not stated in an employment contract then the intellectual property right (IPR) belongs to the inventor. Universities are increasingly exercising their property rights over inventions.

As alluded to earlier, even the presence of the Bayh-Dole Act, Thursby and Kemp (2002) found typically less than half of faculty inventions with commercial disclosure are disclosed to TTOs. Furthermore, the use of an invention disclosure as a proxy for the stock of technology is context specific. The fact that the UK academics are not required to disclose scientific discoveries implies that the true quantity of a university's pool of available technologies for commercialization is unobservable. The use of patents as an indicator of technological input is also problematic because there is substantial variation in quality and in patenting strategies across universities. Some universities generate numerous patents because start-up costs are relatively small. However, they also find that cost of enforcing patents is high and sometimes not worth the effort. In light of the shortcomings of invention disclosures and patents as indicators, we use research expenditure as our measure of technological input.

There is a perception in the academic literature that equity ownership in a university spinout might increase the potential upside gain, which appears to be an attractive option to universities. Evidence from a small set of universities suggests that assuming an equity position in spinout company yields a higher average long-run than the average return on a license (Bray and Lee, 2000). The UK treasury-sponsored Lambert review of business-university collaboration (2003) concluded that British universities were also beginning to emphasize spinout creation.

\footnotetext{
${ }^{1}$ Inventors often use such funds to support graduate students, post-doctoral fellows, and other laboratory costs.
} 
Thus, in order to evaluate technology transfer performance, we need to assess both licensing and spinout activity.

Relative efficiency in university technology transfer is also likely to be related to environmental and organizational factors, such as the presence of a medical school on campus and proxies for the extent to which there is a supportive culture for technology commercialization. A recent study reports that over $60 \%$ of MIT's university licenses result from a biomedical invention. ${ }^{2}$ Bulut and Moschini (2007) conducted an econometric analysis of university licensing income and found that most of the revenue gains were concentrated in private universities with medical schools.

Experience in spinning out companies and licensing may increase the efficiency of a university, as universities 'learn' how to become better at creating spinouts and licenses. Our proxy for experience is the length of time a university has had a TTO. Thus, in our equation 'explaining' relative performance, we include a dummy variable denoting whether the university has a medical school and a measure of the age of the TTO.

Other institutional factors that might explain variation in relative performance are the existence of a university science park or incubator. Science parks are designed to foster the formation and growth of innovative firms, provide an environment which enables large companies to develop relationships with small, innovative firms and promote formal and operational links with universities and other research institutions (Phan et al., 2005). Incubators, on the other hand, are focused on the creation and development of new firms (start ups), which are also concentrated in a limited space.

Finally, regional factors may also be important, such as the R\&D intensity of local firms, the availability of venture capital, and proxies for economic performance. Whether the university is located in a 'research active' region has implications for quality of staff/ agglomeration effects between business and university.

\section{ECONOMETRIC MODEL}

Our framework for constructing measures of relative productivity is stochastic frontier estimation, which was developed independently by Aigner et al. (1977) and Meeusen and van den Broeck (1977). This method generates a production (or cost) frontier with a stochastic error term that consists of two components: a conventional random error ('white noise') and a term that represents deviations from the frontier, or relative inefficiency.

Assume that the production function can be characterized as:

$$
y_{i}=\boldsymbol{X}_{i} \beta+\epsilon_{i}
$$

where the subscript $i$ refers to the $i$ th university, $y$ represents technology transfer output, $\boldsymbol{X}$ denotes a vector of inputs, $\beta$ is the unknown parameter vector, and $\epsilon$ an error term that consists of two components, $\epsilon_{i}=\left(V_{i}-U_{i}\right)$, where $U_{i}$ is a non-negative error term representing technical inefficiency, or failure to produce maximal output given the set of inputs used, and $V_{i}$ is a symmetric error term that accounts for random effects. Thus, we can rewrite Eq. (1) as:

$$
y_{i}=\boldsymbol{X}_{i} \beta+V_{i}-U_{i}
$$

\footnotetext{
${ }^{2}$ See Pressman et al. (1995).
} 
Consistent with Aigner et al. (1977), we assume that the $U_{i}$ and $V_{i}$ have the following distributions:

$$
\begin{aligned}
V_{i} & \sim \text { i.i.d. } N\left(0, \sigma_{v}^{2}\right) \\
U_{i} & \sim \text { i.i.d. } N^{+}\left(0, \sigma_{u}^{2}\right), \quad U_{i} \geq 0 \sim \sigma
\end{aligned}
$$

That is, the inefficiency term, $U_{i}$, is assumed to have a half-normal distribution; i.e., universities are either 'on the frontier' or below it. ${ }^{3}$ Jondrow et al. (1982) specify a functional form for the conditional distribution of $\left[U_{i} /\left(V_{i}-U_{i}\right)\right]$, the mean (or mode) of which provides a point estimate of $U_{i}$.

An important parameter in stochastic frontier models is $\gamma=\sigma_{\mathrm{u}}^{2} /\left(\sigma_{\mathrm{v}}^{2}+\sigma_{\mathrm{u}}^{2}\right) \gamma \sigma$, the ratio of the standard error of technical inefficiency to the standard error of statistical noise, which is bounded between 0 and 1 . Note that $\gamma=0$ under the null hypothesis of an absence of inefficiency, which would imply that all of the variance in the observed error term can be attributed to statistical noise. In our empirical analysis, we will formally test this null hypothesis for each variation of the econometric model.

An important extension of the stochastic frontier literature (see Pitt and Lee, 1981) has been the ability to incorporate determinants of technical inefficiency into these models. This extension is crucial to our analysis, since a chief goal of our study is 'explain' deviations from the frontier (i.e., relative inefficiency in university-industry technology transfer (UITT)). Consistent with Kumbhakar et al. (1991) and Reifschneider and Stevenson (1991), we conjecture that the $U_{i}$ are independently distributed as truncations at zero of the $N\left(m_{i}, \sigma_{\mathrm{u}}^{2}\right) \sigma$ istribution with:

$$
m_{i}=\boldsymbol{Z}_{i} \theta
$$

where $\boldsymbol{Z}$ is a vector of environmental, institutional, and organizational variables that are hypothesized to influence relative efficiency and $\theta$ is a parameter vector. ${ }^{4}$

As shown in Battese and Coelli (1995), simultaneous estimation of the production frontier and inefficiency equations [Eqs. (1) and (2)] by maximum likelihood methods generates estimates of the parameter vectors $\beta$ and $\theta$, which we can use to compute estimates of relative productivity. The authors also note that this method is preferable to a two-stage approach, which involves computing estimates of relative productivity and then running ordinary least squares (OLS) regressions on a set of determinants of establishment-level relative inefficiency. The problem with the two-stage approach is that it yields inconsistent estimates, since the inefficiency effects in the first stage of the model are assumed to i.i.d., while in the second stage they are hypothesized to be a function of university-specific factors.

In Sec. 2, we argued that the process of technology transfer is characterized by multiple outputs: licensing and start-up activity. With multiple outputs, it is appropriate to employ a 'distance' function approach, which can be considered as a generalization of the single output production (or cost) frontier (Fare and Primont, 1990). Distance functions can be estimated using non-parametric or parametric methods. We choose to estimate the frontier parametrically, since our intention is to conduct statistical inference.

The distance function can be expressed as:

$$
\ln D_{\mathrm{o}}=\alpha_{0}+\sum_{m=1}^{M-1} \alpha_{m} \ln y_{m}+\sum_{k=1}^{K} \beta \ln x_{k}+\ln \varepsilon
$$

\footnotetext{
${ }^{3}$ Other distributional assumptions for the inefficiency disturbance that have been invoked are truncated normal and exponential (see Sena, 1999).

${ }^{4}$ As discussed in Battese and Coelli (1995), this model can also incorporate panel data.
} 
Noting that homogeneity implies that:

$$
D_{\mathrm{o}}(x, \omega y)=\omega D_{\mathrm{o}}(x, y)
$$

Hence, if we arbitrarily choose one of the outputs, such as the $M$ th output, and set $\omega=1 / y_{M}$, we obtain:

$$
D_{\mathrm{o}}\left(\frac{x, y}{y_{M}}\right)=D_{\mathrm{o}} \frac{(x, y)}{y_{M}}
$$

For the Cobb-Douglas case, this yields:

$$
\ln \left(D_{\mathrm{o}} / y_{m}\right)=\alpha_{0}+\sum_{m=1}^{M-1} \alpha_{m} \ln y^{*}+\sum_{K=1}^{k} \beta_{K} \ln x_{k}+\ln \varepsilon
$$

where $y *=y_{m} / y_{M}$, and can rewrite the distance function more concisely as:

$$
-\ln \left(D_{\mathrm{o}}\right)-\ln \left(y_{M}\right)=C D\left(\frac{x, y}{y_{M}, \alpha, \beta}\right)
$$

and hence:

$$
-\ln \left(y_{M}\right)=C D\left(\frac{x, y}{y_{M}, \alpha, \beta}\right)+\ln \left(D_{\mathrm{o}}\right)
$$

Hence if we append a symmetric error term $v$ to account for statistical noise and re-write ln $\left(D_{\mathrm{o}}\right)$ as $\mu$, we can obtain the stochastic output distance function, with the usual composite error term $\varepsilon=v+\mu$. We make the standard assumptions that the $v$ are normally distributed random variables, while the $\mu$ are assumed to have a truncated normal distribution:

$$
-\ln \left(y_{M}\right)=C D\left(\frac{x, y}{y_{M}, \alpha, \beta}\right)+v-\mu
$$

In the stochastic frontier approach, the predicted value of the output distance function for the $i$ th firm, $D_{\mathrm{o} i}=\exp (-\mu)$ is not directly observable but must be derived from the composed error term, $\varepsilon_{i}$. Hence, predictions for $D_{\mathrm{o}}$ are obtained using Coelli's Frontier 4.1 program, based on the conditional expectation $D_{\mathrm{o} i}=E\left[(-\mu) \varepsilon_{i}\right]$.

The second equation we estimate is the one, which 'explains' technical inefficiency for the $i$ th university $\left(U_{i}\right)$ :

$$
\begin{aligned}
U_{i}= & \delta_{0}+\delta_{\mathrm{M}} \mathrm{MED}_{i}+\delta_{\mathrm{INC}} \mathrm{INCUB}_{i}+\delta_{\mathrm{SCI}} \mathrm{SCI}_{i}+\delta_{A} \mathrm{AGE}_{i}+\delta_{\mathrm{GDP}} \operatorname{REGGDP}_{i j} \\
& +\delta_{\mathrm{RD}} \operatorname{REGRD}_{i j}+\delta_{\mathrm{VC}} \operatorname{REGVC}_{i j}+\mu_{i}
\end{aligned}
$$

where MED, INCUB, and SCI are dummy variables that are equal to 1 if the university has a medical school, an incubator, or a science park; 0 otherwise, respectively; AGE is the age of the TTO and REGGDP, REGRD, and REGVC are regional industry GDP, R\&D intensity, and venture capital, respectively, where $j$ denotes the region surrounding the university.

\section{DATA}

Our primary data source for US universities is the comprehensive survey conducted by the Association of University Technology Managers (AUTM, 2001). The AUTM file contains annual data on the number of licensing agreements (NOLIC), royalty income generated by licenses (LICINC), university startups generated (USO), research income (RESINC), number of full-time-equivalent employees in the TTO (STAFF), and (external) legal expenditures 
on technology transfer (LEGAL). We also include controls for faculty quality (FACQUAL), which is proxied in the US by the average ranking of a university's doctoral programs and in the UK by the university's average research assessment exercise score. ${ }^{5}$

Corresponding data from the UK were derived from a survey conducted in March 2002, which was then repeated in March 2003. This survey consisted of quantitative and qualitative questions. Given that this is a somewhat new database, we describe it some detail. The survey was mailed to the top 122 UK universities, as ranked by research income. These institutions were identified using the Higher Education Statistics agency (HESA, 2001) publication 'Resources of Higher Education Institutions (2000/2001)'. The remaining 45 universities accounted for only $0.2 \%$ of UK universities' total research grants and contract expenditures in 2001. We received information for 98 of these top 122 universities. Several institutions reported numerous zeros. This indicates that the university was not very active in technology transfer and thus, provided us with only very limited information on this activity. Our final sample consists of only those institutions that provided complete information in both rounds of surveys, as we used lagged inputs and determinants of technical inefficiency.

To test whether our sample is representative, we examined the differences between the universities in our sample of full respondents against the remaining universities. This analysis indicates that our sample of universities relates to those that are more active in technology transfer activities.

\section{EMPIRICAL RESULTS}

Descriptive statistics for the inputs and outputs and determinants of relative efficiency are presented in Table I. Columns 2-4 in Table I present results for the pooled sample. Columns 5-7 and 8-10 contain separate results for the US and the UK, respectively. The representative university in our sample consummated 29 licensing agreements in 2001, earns $\$ 8.4$ million

TABLE I Summary statistics for outputs, inputs, and determinants of relative efficiency for 120 US and UK universities.

\begin{tabular}{|c|c|c|c|c|c|c|c|c|c|}
\hline \multirow[b]{2}{*}{ Variable } & \multicolumn{3}{|c|}{ Pooled } & \multicolumn{3}{|c|}{ US } & \multicolumn{3}{|c|}{$U K$} \\
\hline & $N$ & Mean & $\begin{array}{l}\text { Standard } \\
\text { deviation }\end{array}$ & $N$ & Mean & $\begin{array}{l}\text { Standard } \\
\text { deviation }\end{array}$ & $N$ & Mean & $\begin{array}{l}\text { Standard } \\
\text { deviation }\end{array}$ \\
\hline Number of university spinouts & 120 & 3.88 & 4.15 & 83 & 4.27 & 4.71 & 37 & 3 & 2.31 \\
\hline Number of licenses & 120 & 30.4 & 44.63 & 83 & 39.25 & 50.6 & 37 & 11 & 13.33 \\
\hline Licensing income (\$ mil) & 120 & 8.9 & 29.4 & 83 & 12.6 & 34.8 & 37 & 0.6 & 1.01 \\
\hline Total research income (\$ mil) & 120 & 193 & 247 & 83 & 258 & 270 & 37 & 47.1 & 69.7 \\
\hline External legal IP expense (\$ mil) & 120 & 0.96 & 1.64 & 83 & 1.26 & 1.9 & 37 & 0.30 & 0.46 \\
\hline Number of TTO staff & 120 & 5.41 & 6.13 & 83 & 4.37 & 5.25 & 37 & 6.85 & 7.65 \\
\hline Medical school & 120 & 0.62 & 0.49 & 83 & 0.64 & 0.48 & 37 & 0.57 & 0.50 \\
\hline Science park & 120 & 0.43 & 0.50 & 83 & 0.45 & 0.50 & 37 & 0.38 & 0.49 \\
\hline Age of TTO & 120 & 14.88 & 12.07 & 83 & 17.10 & 13.0 & 37 & 9.24 & 7.24 \\
\hline \multicolumn{10}{|l|}{ Proportion of research } \\
\hline income from business & 120 & 26.86 & 191.53 & 83 & 32.07 & 229.81 & 37 & 15.16 & 27.48 \\
\hline Faculty quality & 120 & 3.48 & 0.86 & 83 & 3.15 & 0.70 & 37 & 4.22 & 0.72 \\
\hline Incubator & 120 & 0.45 & 0.50 & 83 & 0.43 & 0.50 & 37 & 0.49 & 0.51 \\
\hline GDP per capita (\$ mil) & 120 & 28.6 & 5.9 & 83 & 30.4 & 4.3 & 37 & 24.6 & 7.05 \\
\hline $\mathrm{R} \& \mathrm{D}$ as a $\%$ of GDP & 120 & 2.18 & 1.40 & 83 & 2.57 & 1.42 & 37 & 1.30 & 0.86 \\
\hline Regional VC & 120 & 6.08 & 8.53 & 83 & 4.17 & 8.70 & 37 & 10.38 & 6.37 \\
\hline
\end{tabular}

\footnotetext{
${ }^{5}$ Both quality indicators are based on the scale: $1-5$, where 5 is the highest score.
} 
in licensing income, spends $\$ 176$ million on research, employs over five full time workers in the TTO, and spends $\$ 860,000$ on external legal fees to protect its intellectual property. Not surprisingly, US universities have higher levels of outputs and inputs, expect that UK universities appear to hire more TTO staff. The UK figures are somewhat skewed universities with zero values for outputs (and thus, many smaller universities) have been excluded from the analysis.

Table II summarizes the specifications of the technology transfer production functions and determinants of relative efficiency equations that we estimated. There are three output specifications: In Model 1, the outputs are the number of USOs and the number of licenses. Model 2 has the number of USOs and licensing income are the two outputs. Model 3 has three outputs: the number of licenses, licensing income, and the number of USOs. For each of these output specifications, we deal with the cross-country analysis in three ways. In version A, we pool the data. In version B, we have a dummy variable for US universities, while in version $\mathrm{C}$, we interact the US university dummy with the production function parameters.

Table III presents the results of two key hypothesis tests. The findings indicate that we can decisively reject the absence of inefficiency. More importantly, the tests reveal that for each output measure, we should have separate production function parameters for US and UK universities. This provides strong support for version C. For simplicity, we present the results for the distance functions using the Cobb-Douglas functional form. More importantly, the findings in Table III provide strong support for the conjecture that US universities are more efficient at technology transfer than UK universities.

TABLE II Specifications of university technology transfer production functions and determinants of relative efficiency.

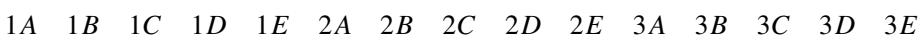

Outputs

USOs

Number of licenses

Licensing income

Inputs

Total research income

External legal IP expenditure

Number of TTO staff

US $\times$ total research income

US $\times$ external legal IP expenditure

US $\times$ number of TTO staff

Faculty quality $\times$ total research income

Faculty quality $\times$ external IP expenditure

Faculty quality $\times$ number of TTO staff

Inefficiency models

Dummy for medical school

Dummy for incubator

Dummy for science park

Age of TTO

Proportion of research income from business

Regional GDP per capita

Regional R\&D

Regional VC

Faculty quality

US university dummy

$\begin{array}{lllllllllllllll}\sqrt{ } & \sqrt{ } & \sqrt{ } & \sqrt{ } & \sqrt{ } & \sqrt{ } & \sqrt{ } & \sqrt{ } & \sqrt{ } & \sqrt{ } & \sqrt{ } & \sqrt{ } & \sqrt{ } & \sqrt{ } & \sqrt{ } \\ \sqrt{ } & \sqrt{ } & \sqrt{ } & \sqrt{ } & \sqrt{ } & & & & & \sqrt{ } & \sqrt{ } & \sqrt{ } & \sqrt{ } & \sqrt{ } & \\ & & & & & \sqrt{ } & \sqrt{ } & \sqrt{ } & \sqrt{ } & \sqrt{ } & \sqrt{ } & \sqrt{ } & \sqrt{ } & \sqrt{ } & \sqrt{ }\end{array}$

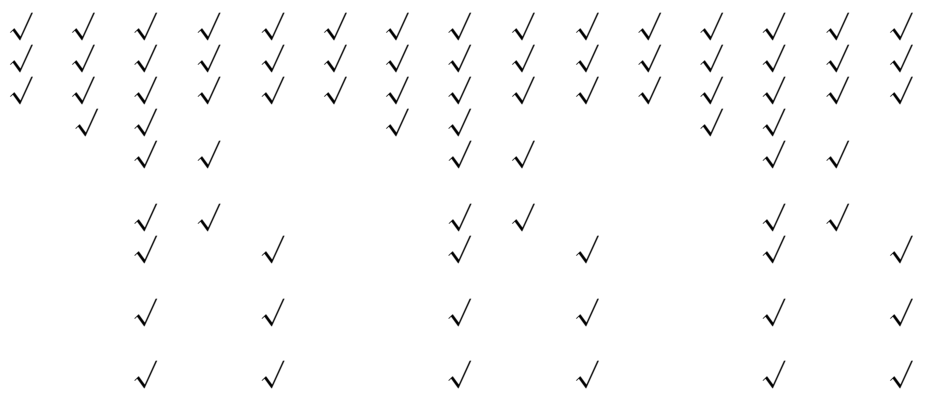

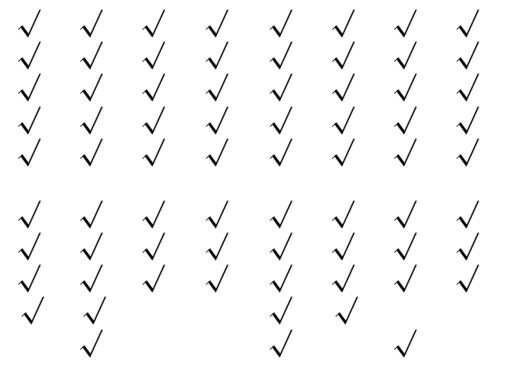

$\begin{array}{ll}\sqrt{ } & \sqrt{ } \\ \sqrt{ } & \sqrt{ } \\ \sqrt{ } & \sqrt{ } \\ \sqrt{ } & \sqrt{ } \\ \sqrt{ } & \sqrt{ } \\ \sqrt{ } & \sqrt{ } \\ \sqrt{ } & \sqrt{ } \\ \sqrt{ } & \sqrt{ } \\ \sqrt{ } & \end{array}$

$\begin{array}{llllll}\sqrt{ } & \sqrt{ } & \sqrt{ } & \sqrt{ } & \sqrt{ } & \sqrt{ } \\ \sqrt{ } & \sqrt{ } & \sqrt{ } & \sqrt{ } & \sqrt{ } & \sqrt{ } \\ \sqrt{ } & \sqrt{ } & \sqrt{ } & \sqrt{ } & \sqrt{ } & \sqrt{ } \\ \sqrt{ } & \sqrt{ } & \sqrt{ } & \sqrt{ } & \sqrt{ } & \sqrt{ } \\ \sqrt{ } & \sqrt{ } & \sqrt{ } & \sqrt{ } & \sqrt{ } & \sqrt{ } \\ \sqrt{ } & \sqrt{ } & \sqrt{ } & \sqrt{ } & \sqrt{ } & \sqrt{ } \\ \sqrt{ } & \sqrt{ } & \sqrt{ } & \sqrt{ } & \sqrt{ } & \sqrt{ } \\ \sqrt{ } & \sqrt{ } & \sqrt{ } & \sqrt{ } & \sqrt{ } & \sqrt{ } \\ \sqrt{ } & \sqrt{ } & & & & \\ & & \sqrt{ } & & & \sqrt{ } \\ \end{array}$


TABLE III Hypothesis tests (nested models).

\begin{tabular}{|c|c|c|c|c|}
\hline Null hypothesis & $\lambda$ & $\begin{array}{c}\text { Critical } \chi_{0.95}^{2} \\
\text { value } \dagger\end{array}$ & Decision & \\
\hline \multicolumn{5}{|c|}{ Output is number of USOs and number of licenses (Model 1) } \\
\hline $\begin{array}{l}\text { There is no significant } \\
\text { difference between US } \\
\text { production parameters } \\
\text { and UK production } \\
\text { parameters }\end{array}$ & $H_{0}: \beta_{i \mathrm{US}}=0, i=1, \ldots, 3$ & 15.44 & 7.81 & Reject $H_{0} ; 1 \mathrm{~B}$ preferred \\
\hline $\begin{array}{l}\text { There is no technical } \\
\text { inefficiency }\end{array}$ & $H_{0}: \gamma=0$ & 23.69 & 11.38 & Reject $H_{0}$ \\
\hline \multicolumn{5}{|c|}{ Output is number of USOs and licensing income (Model 2) } \\
\hline $\begin{array}{l}\text { There is no significant } \\
\text { difference between US } \\
\text { production parameters } \\
\text { and UK production } \\
\text { parameters }\end{array}$ & $H_{0}: \beta_{i \mathrm{US}}=0, i=1, \ldots, 3$ & 14.48 & 7.81 & Reject $H_{0} ; 2 \mathrm{~B}$ preferred \\
\hline $\begin{array}{l}\text { There is no technical } \\
\text { inefficiency }\end{array}$ & $H_{0}: \gamma=0$ & 12.86 & 11.38 & Reject $H_{0}$ \\
\hline \multicolumn{5}{|c|}{ Output is number of USOs, licensing income and licensing revenue (Model 3) } \\
\hline $\begin{array}{l}\text { There is no significant } \\
\text { difference between US } \\
\text { production parameters } \\
\text { and UK production } \\
\text { parameters }\end{array}$ & $H_{0}: \beta_{i \mathrm{US}}=0, i=1, \ldots, 3$ & 15.72 & 7.81 & Reject $H_{0} ; 3 \mathrm{C}$ preferred \\
\hline $\begin{array}{l}\text { There is no technical } \\
\text { inefficiency }\end{array}$ & $H_{0}: \gamma=0$ & 14.49 & 11.38 & Reject $H_{0}$ \\
\hline
\end{tabular}

$\nmid$ The critical values for $\gamma=0$ are obtained from table I of Kodde and Palm (1986) due to the mixed $\chi^{2}$ distribution. All other tests use regular $\chi^{2}$ distributions. The degrees of freedom are $q+1$, where $q$ is the number of parameters which are specified to be 0 .

Table IV contains maximum likelihood estimates of the output elasticities of the distance function. The coefficients on STAFF and LEGAL are, for the most part, positive and highly statistically significant. Research income does not appear to be the critical input in this process. The magnitudes of the estimated coefficients are consistent with previous US studies (Siegel et al., 2003a). We also find evidence of constant or decreasing returns to scale. This represents the increase in the normalized output, holding all output ratios constant, since outputs are on the right hand side of the equation. Therefore, in essence it represents increases in all outputs keeping output composition constant, i.e., larger TTOs generate less licenses, income, and spinouts. This is consistent with our previous UK findings (Chapple et al., 2005), which was based on a single output (either number of licenses or licensing income). In the single output case, we found decreasing returns to scale, which we attributed to either ' $x$ inefficiency' in

TABLE IV Output elasticities of technology transfer inputs.

\begin{tabular}{lccc}
\hline Input & $\begin{array}{c}\text { Model 1C } \\
\text { USO + NUMLIC }\end{array}$ & $\begin{array}{c}\text { Model 2C } \\
\text { USO and LICINC }\end{array}$ & $\begin{array}{c}\text { Model 3C } \\
\text { USO, NUMLIC, LICINC }\end{array}$ \\
\hline$\varepsilon$ RESINC & $0.01(0.04)$ & $0.07(0.06)$ & $-0.02(0.05)$ \\
$\varepsilon$ STAFF & $0.47^{* * * *(0.09)}$ & $0.38^{* * *}(0.11)$ & $0.50^{* * *}(0.09)$ \\
$\varepsilon$ LEGAL & $0.44^{* * *}(0.12)$ & $0.23(0.16)$ & $0.44^{* * *}(0.11)$ \\
$\begin{array}{l}\text { Returns to scale } \\
\text { parameter }\end{array}$ & 0.92 & 0.68 & 0.92 \\
\hline
\end{tabular}

Standard errors are in parentheses.

Significance: $* p<0.1 ; * * p<0.05 ; * * * p<0.01$ 
TABLE V Estimated average technical efficiency: parsimonious model.

\begin{tabular}{lccc}
\hline Output & USO, NUMLIC & USO, LICINC & USO, NUMLIC, LICINC \\
\hline Model & Model 1C & Model 2C & Model 3C \\
Estimated technical efficiency & 0.73 & 0.80 & 0.59 \\
\hline
\end{tabular}

larger TTOs or strategies employed by the TTOs being different, whereby licensing was only undertaken for lucrative inventions.

Turning to the technical inefficiency scores, Table $\mathrm{V}$ reveals that the average efficiency scores are 0.73, 0.80, and 0.59, using the three different sets of outputs. Computing the average of these three values, which is 70.7 , the results suggest that representative institutions could increase technology output by approximately $30 \%$. The results for multiple outputs demonstrate substantially higher levels of efficiency than reported previously for UK universities, where technical efficiency scores were reported as 0.26 (for number of licenses) and 0.29 (licensing income) in single output models (Chapple et al., 2005).

Table VI presents our empirical results relating to the determinants of technical inefficiency. A strong result is that universities with a medical school are more efficient. In contrast, the existence of a university science park does not appear to have an impact on relative efficiency in technology transfer. On the other hand, universities with an incubator appear to be closer to the frontier. This finding is perhaps not surprising, since the stated objective of university incubators is to aid the creation of new firms, typically based on university-owned technologies. However, the age of the university TTO appears to have the opposite effect from that which we proposed. That is, we find that older TTOs are less efficient. One interpretation of this result is that older TTOs are less focused on licensing and, instead, place greater emphasis on alternative mechanisms of technology transfer, such as placement of students and sponsored research. ${ }^{6}$

Direct connections with industry are also important. Universities receiving a higher proportion of their research income from industry are closer to the frontier, although this finding holds only for the three output specifications. Indirect connections between universities and local firms in the region appear to be less important, in terms of explaining the relative efficiency of university technology transfer. Of the regional variables, only R\&D activity appears to have significant explanatory power. Contrary to expectations, the availability of venture

TABLE VI Determinants of technical efficiency: parsimonious model

\begin{tabular}{lccl}
\hline $\begin{array}{l}\text { Inefficiency model: } \\
\text { outputs }\end{array}$ & USO, NUMLIC & USO, LICINC & USO, NUMLIC, LICINC \\
\hline Model & Model 1C & Model 2C & \multicolumn{1}{c}{ Model 3C } \\
MED & $-0.08^{*}(0.02)$ & $-0.04^{*}(0.01)$ & $-0.03^{* *}(0.01)$ \\
INCUB & $-0.02^{* *}(0.009)$ & $-0.02(0.02)$ & $-0.01^{* *}(0.005)$ \\
SCI & $0.13(0.12)$ & $0.05(0.10)$ & $0.16(0.12)$ \\
AGE & $0.01(0.06)$ & $0.01^{* *(0.005)}$ & $0.02^{* *}(0.007)$ \\
PROPBUS & $-0.02(0.02)$ & $-0.01(0.01)$ & $-0.02^{* *}(0.008)$ \\
REGGDP & $0.03(002)$ & $0.00(0.01)$ & $-0.01(0.01)$ \\
REGRD & $-0.02^{* *(0.01)}$ & $0.01(0.02)$ & $-0.01^{* *}(0.004)$ \\
REGVC & $-0.01(0.01)$ & $0.01(0.03)$ & $-0.03(0.04)$ \\
\hline
\end{tabular}

Standard errors are in parentheses. As US dummies are contained in frontier, these are not estimated in the efficiency model.

Significance: $* p<0.1 ; * * p<0.05$; *** $p<0.01$.

\footnotetext{
${ }^{6}$ We are indebted to an anonymous referee for raising this issue.
} 
capital within the university's local region does not appear to have any effect on relative performance.

In future research, we intend to include each university's royalty distribution formula (Link and Siegel, 2005), which measures the fraction of the licensing revenue that accrues to the faculty inventor. It might also be useful to separate private and public US universities.

\section{DISCUSSION AND CONCLUSIONS}

This paper makes two potential contributions to the literature. It is the first cross-country comparison of the relative technology transfer performance of universities. We also extend previous studies by constructing a multiple output distance function, which includes number of licenses, licensing income, and new USOs and equity backed USOs. Previous studies have focused on the number of licenses, licensing income, and university spinout companies in isolation. A key finding is that US universities are more productive than UK universities in technology commercialization.

Our finding that there are constant and possibly, decreasing returns to scale in university technology transfer may reflect the broader-based nature of research disciplines in larger universities. Recent studies suggest that different scientific disciplines require diverse approaches to technology transfer (Owen Smith and Powell, 2001). This could influence the relative importance and feasibility of licensing versus spin-offs between different scientific fields (e.g., life sciences and engineering). Universities may not have the requisite expertise to identify and implement the most appropriate mode of commercialization of inventions across the range of disciplines. This suggests that if universities are to increase the size of their TTOs, they may need to achieve a match between their range of scientific research disciplines and the subject backgrounds of their recruits. Still, based on the evidence presented, we must conclude that there is no evidence to support the assertion that large universities have systematic advantages, relative to smaller institutions.

The finding of the importance of the availability of early stage venture capital, but not venture capital in general, is interesting. Problems associated with UK venture capitalists' investment in early stage high-tech firms are well known (Lockett et al., 2002). There is a need for universities to develop closer links with those venture capital firms that are interested in early stage ventures that are emanating from these research institutions. Not all venture capital firms interested in early stage technology ventures are interested in those created by universities (Wright et al., 2006). Universities need the expertise to recognize and develop strong links with venture capitalists who are interested in investing in spin-offs (so-called 'surrogate' entrepreneurs). An important part of this process may be to ensure that spin-offs are 'investor ready', which may include addressing concerns about the ownership and control of the IP to be incorporated into spin-offs. This lends support to the notion of recruiting more technology transfer officer skills from the private sector and/or attracting business developers from the private sector that want to step into the spin-off during the pre seed phase and develop the business plan.

The analysis suggests implications for policy relating to the balance between spin-offs and licensing in university technology transfer (see e.g., Lambert, 2003; HM Treasury, 2004). The lower TTO efficiency we identify for multiple outputs than for licensing alone emphasizes the need for the development of skills that enable TTOs to select between licensing and spin-off as the most appropriate mode for the commercialization of a particular invention and that there is scope for achieving an appropriate mix of licensing and spin-offs.

It is debatable whether the skills relevant for licensing are synonymous with those required for the development of spin-offs. TTOs' recruitment policies may need to be mindful of 
the need to identify a range of individuals with different skills. For example, developing links with surrogate entrepreneurs may be appropriate for spin-off activity (Franklin et al., 2001), while establishing and strengthening links with suitable industry partners may be more appropriate for licensing activities. Our measure of human capital relates to the number of TTO staff, without controlling for their expertise or quality. Additional research is needed to explore the importance of these human capital characteristics, in terms of 'explaining' relative performance.

\section{Acknowledgements}

We thank Gregory Graff, Catherine Morrison Paul, Matthias Staat, David Zilberman, two anonymous reviewers, and seminar participants at the January 2004 AEA meetings, the June 2004 North American productivity workshop at the University of Toronto, the 2005 second ZEW conference on the economics of innovation and patenting, the March 2007 USDA NC1034 symposium at the University of California, Berkeley, and the University of California at Riverside for insightful comments and suggestions. The first author gratefully acknowledges financial support from the Alfred P. Sloan Foundation through the NBER project on industrial technology and productivity.

\section{References}

Aigner, D., Lovell, C.A.K. and Schmidt, P. (1977) Formulation and Estimation of Stochastic Frontier Production Function Models. Journal of Econometrics, 6(1), 21-37.

Association of University Technology Managers (AUTM) (2001) The AUTM Licensing Survey, Fiscal Year 2000.

Battese, G. and Coelli, T. (1995) A Model for Technical Inefficiency Effects in a Stochastic Frontier Production Function for Panel Data. Empirical Economics, 20, 325-332.

Bray, M.J. and Lee, J.N. (2000) University Revenues from Technology Transfer: Licensing Fees vs Equity Positions. Journal of Business Venturing, 15(5/6), 385-392.

Bulut, H., Moschini, G. (2008) US Universities' Net Returns from Patenting and Licensing: A Quantile Regression Analysis. Economics of Innovation and New Technology, 18(2), in press.

Chapple, W., Lockett, A., Siegel, D. and Wright, M. (2005) Assessing the Relative Performance of U.K. University Technology Transfer Offices: Parametric and Non-parametric Evidence. Research Policy 34, 369-384.

DiGregorio, D. and Shane, S. (2003) Why Do Some Universities Generate More Start-ups Than Others? Research Policy, 32(2), 209-227.

Fare, R. and Primont, D. (1995) Multi-output Production and Duality: Theory and Applications. Boston, MA: Kluwer Academic Publishers.

Franklin, S., Wright, M. and Lockett, A. (2001) Academic and Surrogate Entrepreneurs in University Spin-out Companies. Journal of Technology Transfer, 26(1-2), 127-141.

Higher Education Statistics Agency (HESA) (2001) Resources of Higher Education Institutions (2000/2001). London: Stationery Office.

HM Treasury (2004) Science and Innovation Investment Framework 2004-2014. London: HM Treasury/DTIi/ Department for Education and Skills.

Jensen, R. and Thursby, M. (2001) Proofs and Prototypes for Sale: The Licensing of University Inventions. American Economic Review, 91(1), 240-259.

Jondrow, J., Lovell, C.A.K., Materov, I.S. and Schmidt, P. (1982) On the Estimation of Technical Inefficiency in the Stochastic Frontier Production Function Modal. Journal of Econometrics, 19, 233-38.

Kodde, D. and Palm, F. (1986) Wald Criteria for Jointly Testing Equality and Inequality Restrictions. Econometrica, 54, 1243-1248.

Kumbhakar, S.C., Ghosh, S. and McGuckin, J.T. (1991) A Generalized Production Frontier Approach for Estimating Determinants of Inefficiency in US Dairy Farms. Journal of Business and Economic Statistics, 9, 279-286.

Lambert, R. (2003) Lambert Review of Business-University Collaboration. London: HMSO.

Link, A.N. and Siegel, D.S. (2005) Generating Science-based Growth: An Econometric Analysis of the Impact of Organizational Incentives on University-Industry Technology Transfer. European Journal of Finance, 11(3), $169-182$

Lockett, A., Murray, G. and Wright, M. (2002) Do UK Venture Capitalists still have a Bias against Technology Investments? Research Policy, 31, 1009-1030.

Meeusen, W. and van den Broeck, J. (1977) Efficiency Estimation from Cobb-Douglas Production Functions with Composed Error. International Economic Review, 18, 435-444. 
Owen Smith, J. and Powell, W.W. (2001) To Patent or Not: Faculty Decisions and Institutional Success in Technology Transfer. Journal of Technology Transfer, 26(1-2), 99-114.

Phan, P., Siegel, D. and Wright, M. (2005) Science Parks and Incubators: Observations, Synthesis and Future Research. Journal of Business Venturing, 20(2), 165-182.

Pitt, M.M. and Lee, L. (1981) The Measurement and Sources of Technical Inefficiency in the Indonesian Weaving Industry. Journal of Development Economics, 9, 43-64.

Pressman, L., Guterman, S., Abrams, I., Geist, D. and Nelsen, L. (1995) Pre-production Investment and Jobs Induced by MIT Exclusive Patent Licenses: A Preliminary Model to Measure the Economic Impact of University Licensing. Journal of the Association of University Technology Managers, 7, 77-90.

Reifschneider, D. and Stevenson, R. (1991) Systematic Departures from the Frontier: A Framework for the Analysis of Firm Inefficiency. International Economic Review, 32(3), 715-723.

Sena, V. (1999) Stochastic Frontier Estimation: A Review of the Software Options. Journal of Applied Econometrics, 14(5), 579-586.

Shane, S. (2002) Selling University Technology: Patterns From MIT. Management Science, 48(1), 122-138.

Shane, S. and Stuart, T. (2002) Organizational Endowments and the Performance of University Start-ups. Management Science, 48(1), 154-171.

Siegel, D.S., Waldman, D. and Link, A. (2003a) Assessing the Impact of Organizational Practices on the Relative Productivity of University Technology Transfer Offices: An Exploratory Study. Research Policy, 32(1), 27-48.

Siegel, D.S., Waldman, D., Atwater, L. and Link, A. (2003b) Commercial Knowledge Transfers from Universities to Firms: Improving the Effectiveness of University-Industry Collaboration. Journal of High Technology Management Research, 14, 111-133.

Simar, L. and Wilson, P. (2004) Estimation and Inference in Two Stage, Semi-parametric Models of Production Processes. Mimeo, Department of Economics, University of Texas.

Thursby, J.G., Kemp, S. (2002) Growth and Productive Efficiency of University Intellectual Property Licensing. Research Policy, 31, 109-124.

Thursby, J.G. and Thursby, M. (2002) Who is Selling the Ivory Tower? Sources of Growth in University Licensing. Management Science, 48(1), 90-104.

Thursby, J.G., Jensen, R. and Thursby, M.C. (2001) Objectives, Characteristics and Outcomes of University Licensing: A Survey of Major US Universities. Journal of Technology Transfer, 26, 59-72.

Wright, M., Clarysse, B., Lockett, A. and Binks, M. (2006) University Spin-out Companies and Venture Capital. Research Policy, 35(4), 481-501. 